\title{
Speaking Acquaintances or Helpers in Need: Participation in Civic Associations and Individual Social Capital
}

\author{
Michael Mutz $^{1}$ (D) Ulrike Burrmann ${ }^{2} \cdot$ Sebastian Braun $^{3}$
}

Accepted: 2 September 2020/Published online: 28 September 2020

(C) The Author(s) 2020

\begin{abstract}
It is widely believed that civic associations are capable to produce social capital, here understood as an individual asset resulting from relations of mutual support and assistance. Although hardly anybody denies that socializing is widespread in many civic associations, it still remains to be shown that this socializing provides a genuine commitment to support. This paper explores the relationship between involvement in civic organizations and social support. The data analysed come from a nationwide survey "Organized Sport and Social Capital-Revisited" (OSSCAR) representing the adult population in Germany. Findings show that participation in civic associations is associated with higher levels of social support. This effect is stronger for active participants and weaker for passive members. Path analyses further indicate that this effect is mediated by a person's sociability orientations as well as her commitment to prosocial values. These findings help providing a more nuanced understanding of
\end{abstract}

Electronic supplementary material The online version of this article (https://doi.org/10.1007/s11266-020-00274-x) contains supplementary material, which is available to authorized users.

Michael Mutz

michael.mutz@sport.uni-giessen.de

Ulrike Burrmann

ulrike.burrmann@hu-berlin.de

Sebastian Braun

braun@hu-berlin.de

1 Department of Psychology and Sport Science, Justus-LiebigUniversität Giessen, Giessen, Germany

2 Department of Sport Science, Humboldt-Universität zu Berlin, Berlin, Germany

3 Department of Sport Science, Humboldt-Universität zu Berlin, Berlin, Germany mechanisms of social capital formation in civic associations.

Keywords Social capital · Social connectedness · . Social support · . Civic associations · . Civil society

\section{Civic Associations as Producers of Individual Social Capital}

Much scholarly work has addressed voluntary associations' capabilities to generate, amplify and preserve social capital (e.g. Levi 1996; Newton 2001; Portes 1998; Putnam 1993, 2000; Smith and Kulyniych 2002; Stolle 1998; Wollebæk and Selle 2007; Zimmer and Freise 2008). Some of these studies conceive social capital as a collective good, which unfolds its potentials at the group level, i.e. in communities, regions or nations, while other scholars regard social capital as an individual asset, having its roots in a person's social network (e.g. Bourdieu 1986; Burt 2000; Granovetter 1983; Lin 2001). In the latter perspective, taken up in this paper, social capital connotes the idea that social integration comes with individual benefits. Clubs and associations in the realm of the civil societyfor instance, sport clubs, singing groups, political parties, citizen's initiatives or welfare associations-can thus be conceived as social networks and membership in such associations can broaden and strengthen a person's social capital.

Previous research has already shown that active members of voluntary associations are meeting their friends and acquaintances more often (Brown et al. 2012; Creaven et al. 2018). They report lower levels of loneliness, depression and unsafety (De Donder et al. 2012; Landstedt et al. 2016; Steptoe et al. 2013), a better state of health 
(Piliavin and Siegl 2007), higher levels of trust (Brehm and Rahn 1997; Burrmann et al. 2020; Wollebæk and Strømsnes 2008) and more political engagement (McFarland and Thomas 2006; Van der Meer et al. 2009; Van Stekelenburg et al. 2016).

Despite the large number of studies indicating these effects, most research remains rather sketchy with regard to the function of social capital as an individual utility. For instance, the fact that members of associations feel better socially integrated does not necessarily imply that the social network, which is accessible through the association functions as a carrier of social support in case of need. In some social networks, where people know each other and meet regularly, the readiness for mutual support and assistance is not widespread. In this regard, Østerlund and Seippel (2013) speak of "weak" and "pragmatic" communities and they distinguish these clubs from "strong communities", in which the commitment for reciprocal assistance and help is firmly established. Moreover, actors who constitute a social network may lack the abilities or the resources to offer effective help in a given situation. In this regard, scholars (e.g. Bourdieu 1986, Snijders 1999) pointed out that social capital cannot simply be equalled with the feeling of integration or the size of a social network as it closely depends on the resources that other actors in this network have at their disposal and their willingness to share these resources with network members. Hence, being part of a "weak" network-i.e. weak in resources or in solidarity-would not qualify as capital. It follows that in both cases, an actor may still feel socially integrated, while at the same time the utility function of these group memberships would be marginal.

Moreover, a feature of social capital, according to Bourdieu (1986), is its ability to be converted into other forms of capital, i.e. economic or cultural capital. This conversion may come through practical help, the provision of money or things as well as informational support. While money refers directly to economic capital, practical support usually saves economic capital, because otherwise actors may have bought this support at market prices. Informational support can be regarded as a conversion of social capital into cultural capital: Receiving valuable information or advice from others may be seen as a substitute for a person's own embodied cultural capital. Granovetter (1983) has stressed this informational dimension of social capital and argued that particularly bridging ties, i.e. contacts to people or social groups outside of one's own clique, provide access to a wider range of (novel) information and thus are important for professional careers and social mobility. However, useful information must not be limited to the professional domain, but may also include any financial, medical, educational or legal advice.
Following the work of Snijders (1999), this paper operationalizes social capital as the amount of benefits and support that a person can obtain from her social network. Such an understanding focus on one key dimension of individual social capital, unveiling the surplus value and thus the capital character of a group membership. Moreover, social support is usually linked to financial and/or informational advantages, i.e. addresses the convertibility of social capital into economic and cultural capital. Following this conceptualization of social capital, two research questions are at the core: First, do members of civic associations have an advantage regarding their levels of individual social capital or not? For instance, do they receive more support from their social network compared to non-members, and if yes, how large is this advantage? Assuming that such an advantage exists, the second question refers to the origins of social capital: What produces individual social capital in civic associations? Is it a byproduct of regular interactions with like-minded individuals or the consequence of specific value orientations propagated and acted out in an association?

We will answer these questions based on a German adaptation of the Resource Generator (Van der Gaag and Snijders 2005), an established measure for social capital. A key advantage of this measure is that it directly refers to the resources that become available through membership in social networks. Hence, the Resource Generator (RG) is able to grasp the utility function of that membership, i.e. the additional amount of practical, informational and emotional support that results from the network. Adaptations of the original $\mathrm{RG}$ are found in a variety of studies (Foster and Maas 2016; Kobayashi et al. 2013; Webber and Huxley 2007); however, to our knowledge, this is the first German study that applied a RG-based measure to assess social capital. Moreover, with its endeavour to explicate social capital producing mechanisms, this study may provide a more nuanced understanding of social capital formation in civic associations.

\section{Foundations of Individual Social Capital}

\section{Sociability as a Source of Solidarity and Social Support}

Research on friendship and non-kin sociability has often argued that the development of close, affective, reciprocal social relations has its base primarily in regular contact and frequent interactions (e.g. Verbrugge 1983; Preciado et al. 2012). Coming together on a regular basis enhances the probability that a friendship may develop. In their classic account, Festinger et al. (1950) studied friendship formation among students in a university housing complex 
consisting of 17 separate buildings. Results showed that physical distance between the apartments was crucial for determining the probability that a friendship evolved. Living in the same building heavily increased the probability of becoming friends, but also those with flats close to the postboxes and staircases had more friends compared to students with flats not often passed by others. In a similar study, scholars found that friendships more easily emerged in housing facilities with shared kitchens and bathrooms, as these facilities foster sociality (Yinon et al. 1977). Hence, social proximity seems to follow from regular face-to-face interactions.

Obviously, however, people do not befriend with all of their regular social contacts. On one side, the opportunity to establish closer relations are shaped by the social context in which two people meet. The behavioural rules and codes of conduct, typical for a specific social context, pre-structure social interactions, e.g. whether conversations have a businesslike or personal character or the etiquette is distanced and formal vs. relaxed and casual. On the other side, all these interactions are accompanied by implicit evaluations on whether one's counterpart is likeable or not. If other people are regarded as likeable, interactions become more common and the willingness is raised to discuss a broader spectrum of topics including personal issues. Studies in the field of social psychology have provided ample evidence that attractiveness and sympathy ascribed to somebody are functions of similarities perceived between oneself and that person (e.g. Byrne 1997; Kandel 1978; Hafen et al. 2011; Singh et al. 2017). The more similar two people are-for instance, regarding age, education, political attitudes, musical taste or preferred leisure pursuits-the more likeable they usually regard each other. Perceived similarities may then stimulate a circular process, where interaction leads to perceptions of similarity, sympathy and further interactions. Once initiated, this process may also be fundamental for developing prosocial attitudes towards each other and offering mutual support.

These considerations are useful to assess the potential role of civic associations for social capital production: activities in associations and clubs are usually group activities, which facilitate regular interactions within the same network of people. Moreover, the individuals within this network share some substantial similarities, as they obviously have the same leisure interests, and in most associations - at least in the domain of welfare and politics - they also share the same political and social values. Hence, if people engage in voluntary associations in their leisure time, they are likely to meet like-minded others. Finally, activities in associations are usually accompanied by social activities which allow for informal conversations. Hence, associations can be characterized by attributes which theoretically should foster the development of social bonds and friendships among individuals and solidarity within groups. Hence, they may provide an ideal opportunity structure for the generation of social capital.

Social ties and friendship relations developed in the realm of clubs and associations may only be conceived as individual social capital provided that they yield a "return" for the actor beyond the mere feeling of belonging. Such a return would arise, for instance, in the case that these social relations are reliable enough to bring forth a surplus amount of support and assistance. Strictly spoken, a surplus amount of support for a person is only made available when new acquaintances in the club-generated social network have abilities or resources at their disposal, which are not already included in the person's already existing social network, particularly her circle of family, relatives and friends. However, if the assumption is true that civic associations open up new social relations to persons with specific abilities and resources, then it is likely that actively engaged members of associations, who interact frequently with others, should draw an extra amount of social support out of their club membership.

\section{Prosocial Attitudes and Generalized Reciprocity}

Beyond regular face-to-face interactions with like-minded individuals, social capital formation may also depend on specific value orientations and moral principles, which underlie prosocial behaviour and helpfulness. These value orientations may be developed, enhanced or reproduced in the context of specific civic associations. Portes (1998, p. 8) has coined the term "value introjection" to describe these processes, i.e. the establishment and individual acquisition of solidarity-producing values and norms. Such references towards values and moral principles may be most clearly embedded in the associational cultures of religious and charitable groups, who often propagate benevolence, compassion, Christian love or care for the needy. Hence, in some associations, normative orientations towards prosocial values are part of the association's identity. It is more likely then, that members are confronted regularly with these values and norms, orientate themselves towards them and incorporate them in their own moral compass.

Specific forms of prosocial values may also pervade the associational cultures of clubs beyond the narrow scope of religion and charity. For instance, sport and hobby clubs, singing groups or political movements may directly or indirectly foster prosocial and altruistic values and attitudes. Voluntary associations have been described as "altruistic associations" (Giner and Sarasa 1996), which either aim to work for the benefit of others or for the benefit of its associated members. Moreover, most civic associations depend on active and engaged members, who participate in 
the club's activities and are committed to the clubs' goals. The fact that civic associations are not fully professionalized but rely on volunteer work and the commitment of their members to accept honorary offices has been pointed out as an organizational peculiarity of voluntary associations (Braun 2014). Accordingly, data from Germany show that the majority of roughly two-thirds of all volunteer work takes place within civic associations (Simonson et al. 2016). Due to the fact that voluntary engagement is for the benefit of club members or third parties, it is virtually always enhancing the welfare of others. Hence, it may be assumed that civic associations engender a disposition to act for the sake of others, at least in the proper sense of the association's statutes and aims.

Moreover, any altruistic behaviour can have a modelling function for other club members; hence, it may be noticed and then imitated or reciprocated. Studies have convincingly shown that individuals gear their own social behaviour to perceived norms and codes of conduct (Keizer et al.2008) and they tend to reciprocate helpfulness and cooperation perceived in groups or other persons (Simpson et al. 2018). Therefore, sometimes a single initial "altruistic investment" in a group suffices to evoke a positive dynamic, resulting in higher collective levels of solidarity and helpfulness over time (Fowler and Christakis 2010). Hence, if an association is understood as a social network in which manifold acts of cooperation, altruism and social support are prevalent and can be observed regularly and frequently, then this alone could establish, enhance or stabilize prosocial orientations among the club's membership.

It can thus be conjectured that individuals who participate in civic associations have regular contact with prosocial, altruistic others whose readiness to help and cooperate is potentially high. People who actively participate in civic associations supposedly more often witness and experience in their social interactions acts of helpfulness, cooperation and altruism, and therefore may adopt to a worldview in which prosocial orientations are a main point of reference. Assuming that social capital is, among others, also a function of a person's own prosocial orientation, people with a more altruistic worldview should not only act more altruistically themselves but also receive more support from their social network due to the fact that norms of cooperation and support are enhanced and stabilized reciprocally.

\section{Hypotheses}

As pointed out in the beginning, social capital refers to benefits and support available through a social network. In the simplest way, social capital describes "assets in networks" (Lin 2001, p.3) or the sum of benefits, which an individual can obtain from his ties to other individuals (Snijders 1999, p. 29). One key aspect of these assets and benefits is the amount of support a person can bail out of her social network. The Resource Generator (Snijders 1999; Van der Gaag and Snijders 2005) is able to capture the utility function of social capital, including support with regard to professional, financial, political, leisure-related or health-related aspects.

Derived from the theoretical considerations explained above, four hypotheses are guiding the empirical analyses. First, we assume that members of civic associations have stronger orientations towards sociability compared to nonmembers (Hypothesis \#1). Second, members of civic associations are supposed to have a more pronounced prosocial outlook on society compared to non-members (Hypothesis \#2). Third, members of civic associations receive more support from their social network compared to non-members (Hypothesis \#3). Fourth, we assume that a social support effect of participation in civic associations is mediated by sociability and prosocial orientations. Hence, the direct effect of participation in civic associations on social support should be weakened considerably as soon as sociability and prosocial orientations (the mediating variables) are controlled for (Hypothesis \#4). For hypotheses 1, 2 and 3, it can be further assumed that effects should be stronger for active members than for passive members of the association.

\section{Methods}

\section{Study Design}

This study was part of the research project "Organized Sport and Social Capital-Revisited" (OSSCAR). This project uses a nation-wide online survey to investigate the production of social capital in civic associations $(N=2568)$. The survey was accomplished in cooperation with Kantar Public, a leading organization in public opinion polling and political consultation in Germany. The data were collected from 13 December 2017 to 3 January 2018, with a short interruption during Christmas and New Year's holidays. The sample represents the adult population living in Germany ( $>18$ years) and matches the composition of the population according to age, gender, educational level and residency (East and West Germany). However, respondents with higher educational degrees were slightly overrepresented in the sample. To adjust for these minor deviations from the German population, probability weights are used (see Table 1). Moreover, raw data were checked for conspicuous responding: A small amount of respondents who make use of "straight-lining" (i.e. whose responses show a very small variance or no variance at all) and speedy 
Table 1 Sample characteristics

\begin{tabular}{lll}
\hline & \multicolumn{2}{l}{ Sample composition } \\
\cline { 2 - 3 } & Unweighted sample & Weighted sample \\
\hline Gender & & \\
Male & 50.3 & 48.9 \\
Female & 49.7 & 51.1 \\
Age & & \\
Mean & 48.36 & 49.28 \\
(SD) & $(15.81)$ & $(16.43)$ \\
Education & & \\
Lower secondary & 37.1 & 37.8 \\
Medium secondary & 26.7 & 29.7 \\
Higher secondary & 36.3 & 32.5 \\
Region & & \\
East Germany & 19.4 & 80.1 \\
West Germany & 80.6 & \\
\hline
\end{tabular}

responding (i.e. answering the survey, which was scheduled for $15 \mathrm{~min}$ in less than $5 \mathrm{~min}$ ) were identified and then deleted from the data set.

\section{Measures}

Civic participation Respondents indicated their memberships in a broad range of different civic associations. In total, 14 different voluntary associations were queried, for instance, sports clubs, hobby associations, music groups, unions, parties, citizen initiatives, professional associations, volunteer fire brigades, rescue services or ecological activist groups (Baur and Braun 2003). Overall, 1293 respondents indicated no club memberships (50\%); 1275 respondents hold at least one membership (50\%). Club members additionally had to answer if they "participate regularly in activities", "help regularly" or "exercise an honorary office" in the club. Altogether 813 respondents answered "yes" to at least one of these questions and were categorized as "active members" (32\%); 461 respondents are "passive members" (18\%).

Sociability orientations We used a 7-item scale that refers to a person's perceptions of her network of friends and acquaintances (e.g. "My friends are like a big family"; "I do a lot together with my friends and acquaintances") to measure sociability orientations. The scale is well established in German survey research (Vester et al. 2001; Baur and Braun 2003). Respondents indicated their approval on a 4-point rating scale (1 $=$ "not agree at all" to $4=$ "totally agree"). The scale has a good reliability $(\alpha=.81)$. Values range from 1 to 4 with $M=2.44$ and $S D=0.58$.
Prosocial outlook The 5-item scale for prosocial outlook refers to general attitudes of solidarity, helpfulness and altruism (e.g. "I like to help other people whenever I am able to do so"; "I am prepared to speak up for the interest of others, even if it is inconvenient for me"). The scale is adapted from previous surveys (Vester et al. 2001; Baur and Braun 2003). Answer categories range from $1=$ "not agree at all" to $4=$ "totally agree". The scale has an acceptable reliability $(\alpha=.67)$. Its values range from 1 to 4 with $M=3.16$ and $S D=0.43$.

Social capital To measure the support embedded in a person's network, Snijders has suggested Resource Generator (RG)-based measures, which focus on the support functions of a network and not on network characteristics per se (Snijders 1999; Van der Gaag and Snijders 2005). The RG presents a fixed list of (emergency) situations to respondents and asks to indicate, for which of these situations their social network could provide help. Taken together, these situations cover several domains of life and several dimensions of social support. The RG then quantifies the amount of social support that a person's network of family, friends and acquaintances may provide as the sum of the situations where help is available. Thereby, the RG accounts for the notion that the "aggregation of benefits over alters is not additive" (Snijders 1999, p. 34). Hence, if two or more contacts in a person's social network could provide the same sort of benefits, the additional beneficing provided by the second contact is usually marginal and can be neglected. For that reason, the RG asks respondents only to indicate whether they have at least one person in their network who could provide support in a given situation and not to count the number of contacts from which help would be available. Our situation descriptions closely resemble items from the previous Dutch and British versions of the RG (Van der Gaag and Snijders 2005; Webber and Huxley 2007). However, due to restrictions regarding the length of the survey, the 37-item measure (Van der Gaag and Snijders 2005) had to be shortened. Therefore, we constructed a 13-item RG version, which can be applied in population surveys more easily (see Table 2). The 13 items presented to respondents include situations, where instrumental support (e.g. "someone able to help with a repair in the house"), emotional support (e.g. "someone to turn to when there is a conflict in the family") or informational support (e.g. "someone to consult for a financial advice") is needed. The RG used here can obtain values from 0 (= support available in none of 13 situations) to 13 (= support available in all 13 situations). On average, respondents indicated that their social network could provide support in almost 6 of 13 situations $(M=5.79$; $S D=3.64 ; \min =0 ; \max =13$ ). 
Table 2 13-item German version of the Resource Generator: Item wording and descriptive sample statistics

\begin{tabular}{|c|c|c|c|c|}
\hline \multirow[b]{2}{*}{$\begin{array}{l}\text { In case, you need help in the following situations: Do you know someone in your social } \\
\text { network who could easily support you? Do you know anyone who... }\end{array}$} & \multicolumn{4}{|c|}{ Respondents with social support available (in \%) } \\
\hline & $\begin{array}{l}\text { Non- } \\
\text { members }\end{array}$ & $\begin{array}{l}\text { passive club } \\
\text { members }\end{array}$ & $\begin{array}{l}\text { active club } \\
\text { members }\end{array}$ & $\begin{array}{l}\text { Full } \\
\text { sample }\end{array}$ \\
\hline ...can help with packing and lifting when moving house? & 65 & 68 & 72 & 68 \\
\hline $\begin{array}{l}\text {...can care for your home (e.g. clear letterbox, water flowers), when you are on travel for a } \\
\text { longer time? }\end{array}$ & 64 & 67 & 70 & 67 \\
\hline ...can do the shopping for you when you are ill? & 61 & 64 & 67 & 63 \\
\hline ...can help you with smaller maintenance repairs in the household? & 58 & 64 & 66 & 62 \\
\hline $\begin{array}{l}\text {...would let you stay overnight for a week, if you are unable to use your own place during } \\
\text { that time? }\end{array}$ & 49 & 52 & 58 & 52 \\
\hline ...can discuss current political affairs with you? & 42 & 48 & 53 & 47 \\
\hline ...you can turn to when having disputes in the family? & 41 & 43 & 45 & 42 \\
\hline ...can advise you in financial matters? & 35 & 39 & 48 & 40 \\
\hline ...you can ask if you had to borrow a larger sum of money (for instance, $1000 €$ )? & 32 & 34 & 37 & 34 \\
\hline ...you can turn to when having a conflict at work? & 29 & 32 & 36 & 32 \\
\hline ...can give you a profound medical advice when you are dissatisfied with your physician? & 24 & 26 & 36 & 28 \\
\hline ...can give you a legal advice? & 20 & 24 & 35 & 25 \\
\hline ...can give you a good reference when applying for a job? & 17 & 17 & 24 & 19 \\
\hline
\end{tabular}

Covariates The regression models control for a range of covariates: gender, age, educational level, household income (in 13 categories from $1=$ " $<500 €$ " to 13 $=$ " $>10,000 €$ "), migration background, size of residency as well as for residency in East vs. West Germany. Immigration background refers only to first-generation immigrants. We selected these covariates as they may correlate with civic participation, sociability, prosocial orientations or social support.

\section{Analytical Approach}

Ordinary-least-square (OLS) regression models were applied to assess whether or not active and passive members of civic associations differ in any dependent variable from non-members. Hence, non-members make up the reference group in all models. Our most important dependent variable is social support, but we also test for associations with sociability and prosocial orientations. In the OLS models sociodemographic factors, which may account for selection effects into these organizations, are included. For testing whether sociability and prosocial outlook serve as mediators for the assumed social capital effect of civic participation, we use Andrew Hayes' SPSS Macro PROCESS (Hayes 2018; http://www.processmacro.org/). This modelling tool allows for assessing direct and indirect (mediated) effects and estimates standard errors for mediated effects with the help of bootstrapping procedures.

\section{Results \\ Is Civic Participation Associated with Sociability and Helpfulness?}

First, ordinary-least-squares regressions demonstrate that active members of civic associations generally perceive themselves as more sociable and socially embedded compared to non-members (cf. Table 3, M1a-1b). This difference is shown in models with and without controls, respectively. Model $1 \mathrm{~b}$ includes sociodemographic variables to control for selection effects preceding active participation, but still shows a large advantage regarding social embeddedness for active members of civic associations $(b=.441, p<.01)$. This finding is in line with hypothesis \#1. However, being a passive member in a civic association is not associated with higher levels of sociability compared to non-members $(b=.037, p>.05)$. Participation in the civic domain accounts for $12.8 \%$ of individual differences in sociability orientations. Regarding the control variables, household income and immigrant background are significantly and positively associated with sociability orientations.

Secondly, regression analyses show that members of civic association stand out with a prosocial outlook. According to models $2 \mathrm{a}(b=.122, p<.01)$ and $2 \mathrm{~b}(b=.131$, $p<.01$ ), active members perceive contemporary society as more prosocial and cooperative compared to non-members. This finding lends support to hypothesis \#2. However, passive members also differ from non-members $(b=.058$, 
Table 3 Sociability and prosocial outlook of members of civic associations

\begin{tabular}{|c|c|c|c|c|}
\hline & \multicolumn{2}{|c|}{ Sociability (1-4) } & \multicolumn{2}{|c|}{ Prosocial Outlook (1-4) } \\
\hline & $1 \mathrm{a}$ & $1 b$ & $2 \mathrm{a}$ & $2 b$ \\
\hline \multicolumn{5}{|l|}{ Civic participation } \\
\hline Passive member ${ }^{1}$ & 0.022 & 0.037 & $0.043+$ & $0.058^{*}$ \\
\hline Active member ${ }^{1}$ & $0.447 * *$ & $0.441 * *$ & $0.122 * *$ & $0.131 * *$ \\
\hline \multicolumn{5}{|l|}{ Covariates } \\
\hline Gender: female & - & -0.015 & - & $0.083 * *$ \\
\hline Age & - & 0.000 & - & $0.003 * *$ \\
\hline Educational degree & - & -0.006 & - & 0.006 \\
\hline Household income & - & $0.031 * *$ & - & $0.009 *$ \\
\hline Immigrant background & - & $0.172 * *$ & - & 0.040 \\
\hline Size of residence & - & -0.001 & - & 0.012 \\
\hline Area of residence & - & $0.051^{+}$ & - & $0.058 * *$ \\
\hline Intercept & 2.28 & 2.13 & 3.11 & 2.72 \\
\hline Model fit $\left(\mathrm{R}^{2}\right)$ & .128 & .156 & .016 & .039 \\
\hline
\end{tabular}

Note OLS regression with PROCESS Vs. 3.5. OSSCAR-Study 2017/18. $N=2331$. Indicated are unstandardized regression coefficients (b). ${ }^{1}$ Reference category: non-members. Significance: $+p<.10 / * p<.05 /$ $* * p<.01$

$p<.05, \mathrm{M} 2 \mathrm{~b})$ and perceive prosocial orientations to be more prevailing in society. The difference is small but significant. Civic participation generally accounts for $1.6 \%$ of individual differences in prosocial outlook. Control variables indicate that prosocial views are more widespread among females, older individuals, those living in high-income households as well as among West-German residents.

\section{Is Civic Participation Associated with Social Capital?}

A set of five regression models tests whether civic participation is associated with individual social capital that a person can generate through her social network. The measure for social capital is based on the Resource Generator; hence, it varies between 0 and 13, depending on the number of situations in which a person has a contact in their network, who could provide effective help. The simple models without mediators (cf. Table 4, M3a-3b) show that active participation in the civic domain is significantly associated with more social capital. Active members are convinced to find social support in roughly one more (emergency) situation compared to non-members $(b=.967, p<.01, \mathrm{M} 3 \mathrm{~b})$. This finding supports our third hypothesis. For passive members, a significant association is also shown, although the size of the effect is smaller $(b$ $=.405, p<.05, \mathrm{M} 3 \mathrm{~b})$. The simplest model with only active and passive participation as predictors accounts for $1.4 \%$ of individual differences in social capital. Regarding the control variables, females, better educated and financially better-off individuals report to have access to more support within their social network.

\section{Mediation Analysis}

One of our key assumptions (see Hypothesis \#4) was that the surplus of social capital generated from membership in civic associations is mediated by sociability and prosocial orientations. The mediation analysis demonstrates that the total effect of active participation in civic associations on individual social capital ( $b=.967$, M3b) can be separated into the direct effect $(.312, \mathrm{M} 3 \mathrm{e})$, which is marginally significant, and two indirect effects: The first indirect effect is mediated by sociability orientations $(b=.315, S E=.064$, $\beta=.086, p<.01)$ and the second is mediated by prosocial outlook $(b=.339, S E=.056, \beta=.092 p<.01)$. Both mediation effects are highly significant. Moreover, the mediation analysis for passive membership indicates that the total effect on social support $(b=.405$, M3b) can be separated into the non-significant direct effect $(b=.228, \mathrm{M} 3 \mathrm{e})$ and two indirect effects, from which only one is significant: The indirect effect mediated by sociability orientations $(b$ $=.027, S E=.024, \beta=.007, p>.05)$ is not significant, whereas the effect mediated by prosocial outlook is significant at the .05-level $(b=.150, S E=.062, \beta=.041$, $p<.05)$. The significant paths are illustrated in Fig. 1, which shows the full mediation model for the social capital effects of civic participation. lated another set of regression models for which we further distinguished the active members into "volunteers", i.e.
For checking the robustness of these results, we calcu- 
Table 4 Social support received by members of civic associations

\begin{tabular}{|c|c|c|c|c|c|}
\hline & \multicolumn{5}{|c|}{ Social Support (Resource Generator, 0-13) } \\
\hline & $3 \mathrm{a}$ & $3 b$ & $3 \mathrm{c}$ & $3 \mathrm{~d}$ & $3 e$ \\
\hline \multicolumn{6}{|l|}{ Civic participation } \\
\hline Passive member ${ }^{1}$ & $0.464^{*}$ & $0.405^{*}$ & $0.368+$ & 0.240 & 0.228 \\
\hline Active member ${ }^{1}$ & $.996 * *$ & $0.967 * *$ & $0.397 *$ & $0.592 * *$ & $0.312+$ \\
\hline \multicolumn{6}{|l|}{ Mediators } \\
\hline Sociability & - & - & $1.324 * *$ & - & $0.714 * *$ \\
\hline Prosocial Outlook & - & - & - & $2.880 * *$ & $2.594 * *$ \\
\hline \multicolumn{6}{|l|}{ Covariates } \\
\hline Gender: female & - & $1.096 * *$ & $1.130 * *$ & $0.856^{* *}$ & $0.892 * *$ \\
\hline Age & - & 0.001 & 0.001 & -0.008 & -0.008 \\
\hline Educational degree & - & $0.329 * *$ & $0.337 * *$ & $0.314 * *$ & $0.318 * *$ \\
\hline Household income & - & $0.149 * *$ & $0.108 * *$ & $0.123 * *$ & $0.104 * *$ \\
\hline Immigrant background & - & -0.435 & $-0.653^{*}$ & $-0.548+$ & $-0.661^{*}$ \\
\hline Size of residence & - & 0.039 & 0.036 & 0.006 & 0.009 \\
\hline Area of residence & - & -0.097 & -0.166 & -0.271 & -0.284 \\
\hline Intercept & 5.50 & 1.95 & -0.92 & -5.90 & -6.63 \\
\hline Model fit $\left(\mathrm{R}^{2}\right)$ & .014 & .062 & .100 & 0.166 & 0.176 \\
\hline
\end{tabular}

Note OLS regression with PROCESS Vs. 3.5. OSSCAR-Study 2017/18. $N=2331$. Indicated are unstandardized regression coefficients (b). ${ }^{1}$ Reference category: non-members. Significance: $+p<.10 / * p<.05 /$ $* * p<.01$

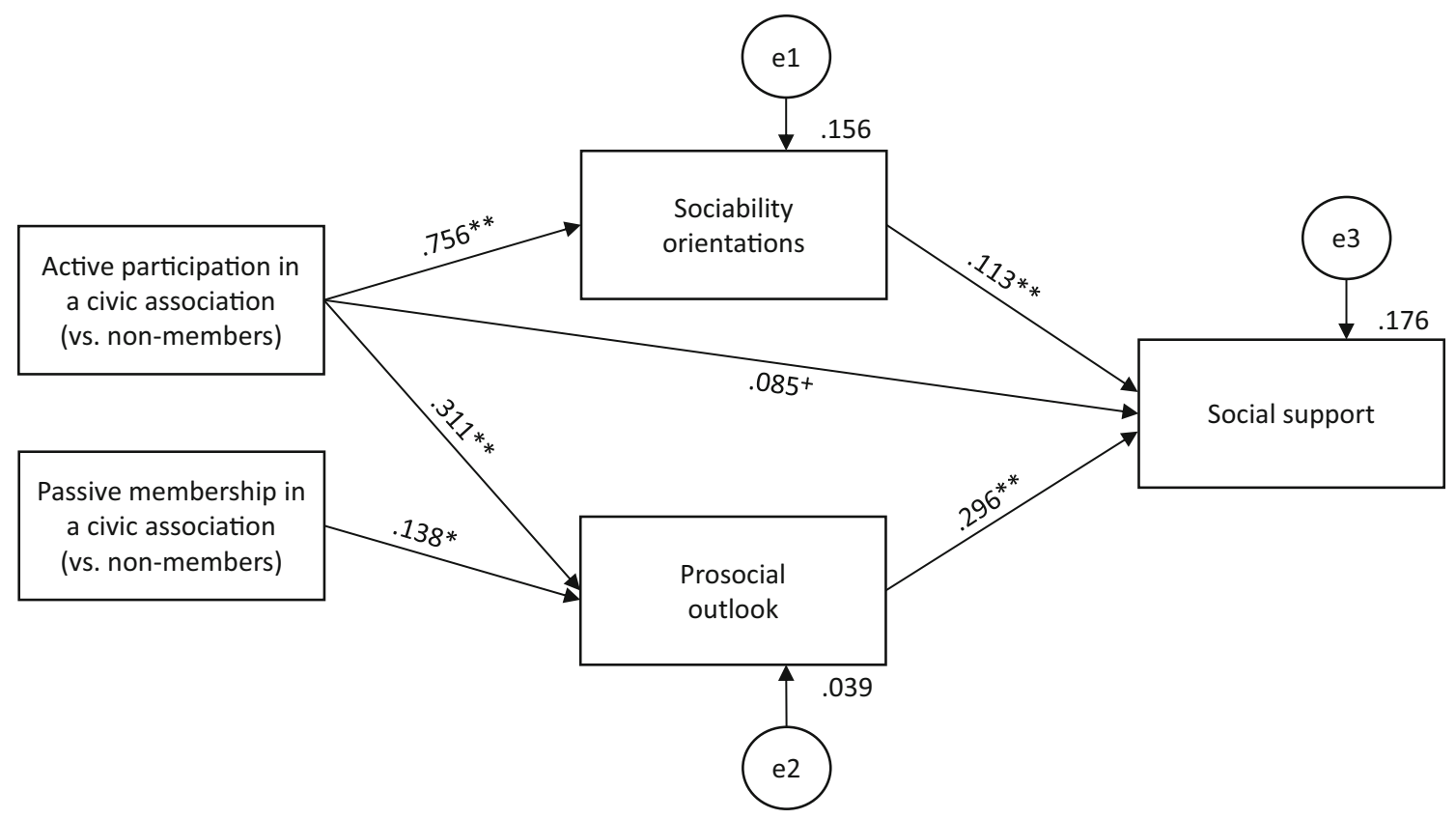

Fig. 1 Mediation model for the social support effects of civic participation. Note Based on OLS regressions including sociodemographic controls. Model parameters estimated with PROCESS Vs. 3.5. Indicated are standardized coefficients $(\beta)$. Significance: $+p<.10 / * \mathrm{p}<.05 / * * p<.01$

who help regularly or hold an office in the association, and "active participants", i.e. who take part regularly in the association's activities, but do not volunteer. These findings are documented in an online appendix accompanying this paper. The additional results largely conform to the results presented here, but further show that the total effect of volunteering on social capital is fully mediated by sociability orientations and prosocial outlook, whereas for active participation a partial mediation is found with a small and significant direct effect remaining. 


\section{Discussion and Conclusions}

The present study used large-scale survey data to analyse the associations between civic participation and one key aspect of individual social capital, namely the support generated from social networks. Based on a Germany-wide representative online survey, findings demonstrate that active participation in civic associations is associated positively with the social capital available from a person's social network. Active members of voluntary associations (and to a lesser degree also passive members) receive more support from their social network compared to non-members. Precisely, they can count on their network of family, friends and acquaintances in a wider range of (emergency) situations where they are in need for assistance.

This effect is mediated by sociability attitudes and prosocial orientations. We have argued that socializing and friendship formation are integral parts of many civic associations, especially those in the domain of leisure and culture. And we elaborated that civic participation also strengthens a person's prosocial outlook, because in many voluntary associations active participants experience mutual cooperation and helpfulness, and they adapt to generalized reciprocity norms. Our findings buttress the assumption that social capital effects of civic associations are mediated-in large parts, at least—by sociability and prosocial orientations. With regard to active members, the total effect on social support was divided into three almost equal components: a direct effect, an indirect effect mediated by sociability and an indirect effect mediated by prosocial outlook. Moreover, not only active participants scored higher in social support, sociability and prosocial outlook, but also for passive members, a slight advantage in social capital compared to non-members was demonstrated. However, this small effect for passive members was almost completely mediated by prosocial orientations.

Our findings contribute to the state of research in several ways: Distinguishing this study from previous research, our measure of social capital goes beyond subjective "feelings of belonging" or "social connectedness" (e.g. Hoye et al. 2015) and highlights the benefits, i.e. the capital character, of an individual's social network. Moreover, as social support is related to health, the additional amount of social support received through associational contacts may help to foster mental and physical well-being (Piliavin and Siegl 2007; Steptoe et al. 2013). Moreover, the study gives some indications which mechanisms may produce the social capital effect of voluntary associations: Associations may foster sociality, i.e. frequent interactions with like-minded others and this sociality per se may be a base for solidarity and mutual support. In addition, prosocial values can be inscribed into the normative DNA of an association, so that reciprocated cooperation and altruism among members become a moral obligation.

Findings presented here show average effects over all types of clubs but do not allow for conclusions on specific types of voluntary associations. Previous research has pointed out that social capital effects vary between different types of associations. For instance, Van der Meer et al. (2009) have shown that members of leisure, activist and interest organizations vary with regard to political attitudes as well as trust in political institutions. Voicu and Voicu (2016) found significant differences between associations with regard to gender equality values: Whereas members of religious and sport organizations were more conservative, members of charity organizations turned out to be more liberal. Burrmann et al. (2020) document differences in social trust levels between members of inwardand outward-oriented associations. These differences between associations may be due to socialization process that result from engagement and activities within that organization. However, they may also be due to selection processes that precede membership, given that studies pointed to differences in membership structures between specific types of associations (Bekkers et al. 2008; Voicu and Serban 2012). Although differences between types of associations were not in the scope of the present study, it can be argued that many inward-oriented associations (e.g. organizations in the domain of leisure) may produce higher degrees of sociality, whereas outward-oriented organizations (e.g. activist and charity associations) may generate higher amounts of prosocial values. Hence, our findings may inspire more fine-grained research on particular types of associations and their specific mechanisms of social capital production.

Despite its contribution to the state of research, this study has also some limitations: First, the cross-sectional design of the survey does not allow for testing causality. The causal assumptions put forward in this paper are based on theoretical and plausibility considerations. Hommerich (2015), for instance, argues that socially disconnected individuals dissociate themselves from civil engagement, thus lending support to the reversed causal mechanism. Likewise, individuals with initial high levels of sociability and prosocial values as well as a supportive social network may be more inclined to participate in certain voluntary associations (e.g. charity organization) or to volunteer in said organizations. These arguments, however, do not contradict the line of reasoning put forward here, as both paths of influence do not exclude each other, but can coexist (Piliavin and Siegl 2007; Sirven and Debrand 2012).

Secondly, we were not able to use the original 37-item Resource Generator proposed by Van der Gaag and Snijders (2005), but had to shorten the measure to 13 items. 
These adaptations have been applied in other countries as well (e.g. Webber and Huxley 2007); however, this undermines comparability over countries and studies. Finally, our endeavour to focus on the extra dose of social support provided by social networks does in no way mean that a sense of belonging is less important. The feeling of affiliation and connectedness is undeniably important for well-being and happiness (e.g. Matsushima and Matsunaga 2015). However, the term social capital implies a utility function beyond a simple "feel good"-effect.

Taken together, this paper allows for several conclusions: Based on large-scale representative survey data from Germany, it shows that active participation in civil society organizations comes with individual benefits, as actors then receive support from their social network in a wider range of situations. The social capital effect of active participation is associated with specific orientations established in the realm of civic associations: firstly, sociality attitudes that place importance on social interactions with likeminded people, and secondly, prosocial values that address the importance of helping and cooperation. Fostering these orientations in associations' cultures may yield benefits for individuals and communities alike.

FundingOpen Access funding provided by Projekt DEAL.

\section{Complaince with Ethical Standards}

Conflict of interest The authors declare that they have no conflict of interest.

Open Access This article is licensed under a Creative Commons Attribution 4.0 International License, which permits use, sharing, adaptation, distribution and reproduction in any medium or format, as long as you give appropriate credit to the original author(s) and the source, provide a link to the Creative Commons licence, and indicate if changes were made. The images or other third party material in this article are included in the article's Creative Commons licence, unless indicated otherwise in a credit line to the material. If material is not included in the article's Creative Commons licence and your intended use is not permitted by statutory regulation or exceeds the permitted use, you will need to obtain permission directly from the copyright holder. To view a copy of this licence, visit http://creativecommons. org/licenses/by/4.0/.

\section{References}

Baur, J., \& Braun, S. (2003). Integrationsleistungen von Sportvereinen als Freiwilligenorganisationen. Aachen: Meyer \& Meyer.

Bekkers, R., Völker, B., Van der Gaag, M., \& Flap, H. (2008). Social networks of participants in voluntary associations. In N. Lin \& B. Erickson (Eds.), Social capital: An international research program (pp. 185-205). Oxford: Oxford University Press.

Bourdieu, P. (1986). The forms of capital. In J. Richardson (Ed.), Handbook of theory and research for the sociology of education (pp. 241-258). New York: Greenwood.

Braun, S. (2014). Voluntary associations and social capital - inclusive and exclusive dimensions. In M. Freise \& T. Hallmann (Eds.),
Modernizing democracy. Associations and associating in the 21st century (pp. 59-70). New York: Springer.

Brehm, J., \& Rahn, W. (1997). Individual-level evidence for the causes and consequences of social capital. American Journal of Political Science, 41(3), 999-1023.

Brown, K. M., Hoye, R., \& Nicholson, M. (2012). Self-esteem, selfefficacy, and social connectedness as mediators of the relationship between volunteering and well-being. Journal of Social Service Research, 38(4), 468-483.

Burrmann, U., Braun, S., \& Mutz, M. (2020). In whom do we trust? the level and radius of social trust among sport club members. International Review for the Sociology of Sport, 55(4), 416-436.

Burt, R. S. (2000). The network structure of social capital. Research in Organizational Behavior, 22, 345-423.

Byrne, D. (1997). An overview (and underview) of research and theory within the attraction paradigm. Journal of Social and Personal Relationships, 14(3), 417-431.

Creaven, A. M., Healy, A., \& Howard, S. (2018). Social connectedness and depression: Is there added value in volunteering? Journal of Social and Personal Relationships, 35(10), 14001417.

De Donder, L., De Witte, N., Buffel, T., Dury, S., \& Verté, D. (2012). Social capital and feelings of unsafety in later life: A study on the influence of social networks, place attachment, and civic participation on perceived safety in Belgium. Research on Aging, 34(4), 425-448.

Festinger, L., Schachter, S., \& Back, K. (1950). Social pressures in informal groups; a study of human factors in housing. Oxford: Harper.

Foster, K. A., \& Maas, C. D. (2016). An exploratory factor analysis of the resource generator-United States: A social capital measure. The British Journal of Social Work, 46(1), 8-26.

Fowler, J. H., \& Christakis, N. A. (2010). Cooperative behavior cascades in human social networks. Proceedings of the National Academy of Science, 107(12), 5334-5338.

Giner, S., \& Sarasa, S. (1996). Civic altruism and social policy. International Sociology, 11(2), 139-159.

Granovetter, M. S. (1983). The strength of weak ties: A network theory revisited. Sociological Theory, 1(6), 201-233.

Hafen, C. A., Laursen, B., Burk, W. J., Kerr, M., \& Stattin, H. (2011). Homophily in stable and unstable adolescent friendships: Similarity breeds constancy. Personality and Individual Differences, 51(5), 607-612.

Hayes, A. F. (2018). Mediation, moderation, and conditional process analysis. New York: Guilford Press.

Hommerich, C. (2015). Feeling disconnected: Exploring the relationship between different forms of social capital and civic engagement in Japan. Voluntas, 26(1), 45-68.

Hoye, R., Nicholson, M., \& Brown, K. (2015). Involvement in sport and social connectedness. International Review for the Sociology of Sport, 50(1), 3-21.

Kandel, D. B. (1978). Similarity in real-life adolescent friendship pairs. Journal of Personality and Social Psychology, 36(3), 306312.

Keizer, K., Lindenberg, S., \& Steg, L. (2008). The spreading of disorder. Science, 322(5908), 1681-1685.

Kobayashi, T., Kawachi, I., Toshihide, I., Suzuki, E., \& Soshi, T. (2013). Individual-level social capital and self-rated health in Japan: An application of the Resource Generator. Social Science and Medicine, 85, 32-37.

Landstedt, E., Almquist, Y. B., Eriksson, M., \& Hammarström, A. (2016). Disentangling the directions of associations between structural social capital and mental health. Social Science and Medicine, 163, 135-143. 
Levi, M. (1996). Social and unsocial capital: A review essay of Robert Putnam's making democracy work. Politics \& Society, 24 (1), 45-55.

Lin, N. (2001). Social capital. A theory of social structure and action. Cambridge: Cambridge University Press.

Matsushima, M., \& Matsunaga, Y. (2015). Social capital and subjective well-being in Japan. Voluntas, 26(4), 1016-1045.

McFarland, D. A., \& Thomas, R. J. (2006). Bowling Young: How youth voluntary associations influence adult political participation. American Sociological Review, 71(3), 401-425.

Newton, K. (2001). Trust, social capital, civil society, and democracy. International Political Science Review, 22(2), 201-214.

Østerlund, K., \& Seippel, Ø. (2013). Does membership in civil society organizations foster social integration? The case of Danish voluntary sport organizations. Journal of Civil Society, 9(4), 123.

Piliavin, J. A., \& Siegl, E. (2007). Health benefits of volunteering in the Wisconsin longitudinal study. Journal of Health and Social Behavior, 48(4), 450-464.

Portes, A. (1998). Social capital: Its origins and applications in modern sociology. Annual Review of Sociology, 24, 1-24.

Preciado, P., Snijders, T. A. B., Burk, W. J., Stattin, H., \& Kerr, M. (2012). Does proximity matter? distance dependence of adolescent friendships. Social Networks, 34(1), 18-31.

Putnam, R. D. (1993). Making democracy work: Civic traditions in modern Italy. New Jersey: Princeton University Press.

Putnam, R. D. (2000). Bowling alone: America's declining social capital. In L. Crothers \& C. Lockhart (Eds.), Culture and Politics. New York: Palgrave Macmillan.

Simonson, J., Vogel, C. \& Tesch-Römer, C. (2016). Freiwilliges Engagement in Deutschland - Der Deutsche Freiwilligensurvey 2014. Berlin: Bundesministerium für Familie, Senioren, Frauen und Jugend.

Simpson, B., Harrell, A., Melamed, D., Heiserman, N., \& Negraia, D. V. (2018). The roots of reciprocity: Gratitude and reputation in generalized exchange systems. American Sociological Review, 83 (1), 88-110.

Singh, R., Wegener, D. T., Sankaran, K., Bhullar, N., Ang, K., Chia, P., et al. (2017). Attitude similarity and attraction: Validation, positive affect, and trust as sequential mediators. Personal Relationships, 24(1), 203-222.

Sirven, N., \& Debrand, T. (2012). Social capital and health of older Europeans: Causal pathways and health inequalities. Social Science and Medicine, 75(7), 1288-1295.

Smith, S. S., \& Kulyniych, J. (2002). It may be social, but why is it capital? The social construction of social capital and the politics of language. Politics \& Society, 30(1), 149-189.

Snijders, T. A. B. (1999). Prologue to the measurement of social capital. La Revue Tocquecille, 20(1), 27-44.

Steptoe, A., Shankar, A., Demakakos, P., \& Wardle, J. (2013). Social isolation, loneliness, and all-cause mortality in older men and women. Proceedings of the National Academy of Sciences, 110 (15), 5797-5801.

Stolle, D. (1998). Bowling together, bowling alone: the development of generalized trust in voluntary associations. Political Psychology, 19(3), 497-525.

Van Der Gaag, M., \& Snijders, T. A. B. (2005). The resource generator: Social capital quantification with concrete items. Social Networks, 27(1), 1-29.

Van der Meer, T. W. G., te Grotenhuis, M., \& Scheepers, P. L. H. (2009). Three types of voluntary associations in comparative perspective: the importance of studying associational involvement through a typology of associations in 21 European countries. Journal of Civil Society, 5(3), 227-241.

Van Stekelenburg, J., Klandermans, B., \& Akkerman, A. (2016). Does civic participation stimulate political activity? Journal of Social Issues, 72(2), 286-314.

Verbrugge, L. M. (1983). A research note on adult friendship contact: A dyadic perspective. Social Forces, 62(1), 78-83.

Vester, M., von Oertzen, P., Geiling, H., Hermann, T., \& Müller, D. (2001). Soziale Milieus im gesellschaftlichen Strukturwandel. Frankfurt: Suhrkamp.

Voicu, B., \& Şerban, M. (2012). Immigrant involvement in voluntary associations in Europe. Journal of Ethnic and Migration Studies, $38(10), 1569-1587$.

Voicu, M., \& Voicu, B. (2016). Civic participation and gender beliefs: An analysis of 46 countries. Czech Sociological Review, 52(3), 321-345.

Webber, M. P., \& Huxley, P. J. (2007). Measuring access to social capital: the validity and reliability of the Resource Generator-UK and its association with common mental disorder. Social Science and Medicine, 65(3), 481-492.

Wollebæk, D., \& Selle, P. (2007). Origins of social capital: Socialization and institutionalization approaches compared. Journal of Civil Society, 3(1), 1-24.

Wollebæk, D., \& Strømsnes, K. (2008). Voluntary associations, trust, and civic engagement: A multilevel approach. Nonprofit and Voluntary Sector Quarterly, 37(2), 249-263.

Yinon, Y., Goldenberg, J., \& Neeman, R. (1977). On the relationship between structure of residence and formation of friendships. Psychological Reports, 40(3), 761-762.

Zimmer, A., \& Freise, M. (2008). Bringing society back in: Civil society, social capital, and third sector. In W. Maloney \& J. W. van Deth (Eds.), Civil society and governance in Europe (pp. 1945). Northampton: Edgar Elgar.

\section{Publisher's Note}

Springer Nature remains neutral with regard to jurisdictional claims in published maps and institutional affiliations. 